\title{
Long Term Analysis of Nuclear Containment Structure Considering Material Non-linearity and Geometric Non- linearity Effects
}

\author{
Niteesh Halagatti ${ }^{\# 1}$, Rajashekar Swamy ${ }^{\# 2}$, Santhosh H P ${ }^{\# 3}$

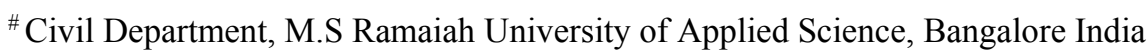 \\ ${ }^{1}$ nitish.halagatti@gamil.com \\ ${ }^{2}$ rajashekharswamy.ce.er@msruas.ac.in \\ ${ }^{3}$ hpsanthosh.ce.er@msruas.ac.in
}

\begin{abstract}
Demand for energy is increasing day by day across the world resulting in construction of more number of atomic power stations. Critical facilities such as nuclear containment structure design require an exact and accurate assessment of aging requirements, because any failure of these facilities causes great threat to society.

In the present study nuclear containment structure is modelled according to specification of kudankulam nuclear containment structure, static and dynamic analysis is carried out for the same site location. In order to overcome the failure of much nuclear containment structure due to adverse durability effects before their expected design life, long term analysis of nuclear containment structure is carried out by considering geometric non-linearity, material non-linearity and temperature effects for period of 100 years using relevant standard codes. The results obtained in this study shows that the long term deflection by considering the effects of creep, shrinkage and temperature are within permissible limit according to clause of I.S 4562000 is evaluated for period of 100 years.
\end{abstract}

Keyword - P-Delta analysis, Creep, Shrinkage, IS 456- 2000, CEB-FIP 1990

\section{INTRODUCTION}

Earlier nuclear reactors are designed maximum for a period of 40 years. Currently in order to improve the profit and to enhance the nuclear share of the electricity supply, presently nuclear industries are significantly concentrating on expansion of the life of nuclear power plant. As of May 2016, 444 nuclear reactors are operating across 30 countries for the production of electricity and 63 new nuclear power plants are in the construction phase in 15 countries. Across India Twenty atomic reactors with 4780 MW capacity are in operation and seven more reactors of $5300 \mathrm{MW}$ in construction stage.

Increasing demand for nuclear energy across the world have increased concerns towards the safety of nuclear power plant as any basic harm to any these atomic reactors resulting in serious risk of radiation effects, real health issues and also organic and ecological dangers. Florida nuclear power plant accident in 2009 and Tarapur first and second boiling reactor units operation are stopped after 2011 Fukushima accident, Tree mile island accident. These accidents increased fear from atomic reactors hence nuclear board is concentrating more on safety issues. Ageing is a continuous time-dependent loss of quality of materials, caused by the operating conditions like temperature, irradiation, corrosion, abrasion, erosion and combination of all factors.

The International Energy Agency states as follows "In the coming decade life of nuclear power plant will be the most significant factors for generation of electricity hence if there is no change in principles and policies of atomic energy"

\section{BACKGROUND THEORY}

N. M. Bhandari, Banti A. Gedam and AkhilUpadhyay [1] (2009) invested creep and shrinkage of HPC for period of nine hundred days using 4 existing material model code and lastly validation of results is done with experimental study. The results of this study shows that the shrinkage \& creep result shows that the CEB FIP 1990 model codal provisions is a closer match with $2 \%$ deviation of experimental data, whereas the ACI 209R92 , B3 and GL2000 models are overestimating deviational coefficient between $31 \%$ to $66 \%$ for creep and 46 to $89 \%$ for shrinkage.

Robert S. Dunham Randy J. James, and Joseph Y [2] 2010 studied aging behaviour of Nuclear power plant by Modelling and analysis of NPP structure with advanced technology. The results of this study shows that Advanced modelling and simulation techniques are important in evaluating desired and unusual structural behaviour to enhance the safety operation of NPP Structure which is near to their design life and Time- 
dependent material degradation factors like temperature and alkali aggregate reaction that can affect the long duration behaviour of NPP structures

Rospars .C, P. Bisch, G. Moreaur, Erlicher S and Ruocci. G [14] in year 2015 studied Analysis of cracking pattern in reinforced concrete members subjected to shear cyclic load. Displacement and strain fields in shear wall are evaluated using digital images correlation, cracks patterns are characterised in terms of crack spacing, orientation and average crack width, a comparative study of evolutions of cracks for two different types of cyclic loading is carried out and maximum and residual crack width at ultimate loading case are analysed results reveals that Shear cyclic load test on concrete revels that there is monotonically increase of crack width and propagation of cracks on the concrete structure indicates about the stabilisation of cracking pattern.

N. Dawood, and H. Marzouk, in 2013 provides Design Guidelines criteria for Controlling of cracks in a thick high-Strength Concrete members of an off shore structures in order to determine the behaviour of cracks and prevention measures need to be adopted to control cracks in a thick HSC members by developed empirical equations. Authors found that greater the value of bar spacing and cover of concrete, results in reduction of maximum allowed steel stress. For controlling cracks there is no significant effect of concrete strength on maximum steel tensile stress. Crack formation can be avoided by using lesser diameter bar having a larger steel stress. And finally they concluded the best empirical approach. An easy way to comply with the conference paper formatting requirements is to use this document as a template and simply type your text into it.

\section{III.METHODOLOGY}

Finite element modelling of nuclear containment structure is carried out according to specification of Kudankulam nuclear power plant project, which is located along the gulf coast of Mannar at $25 \mathrm{~km}$ northeast of Kanyakumari India. Static and dynamic analysis is carried out using ETABS according to Indian standards for same site location.

In the present study nuclear containment structure is designed and analysed for a period of hundred years against material non-linearity, geometric non-linearity and varying temperature load of $+50 \mathrm{oc}$ in order to ensure safety and serviceable for entire design life. For geometric non - linearity p-delta analysis is carried out according to I.S 1893 (part 1) 2002 and UBC 97. Whereas For material non-linearity time dependent properties like creep and shrinkage analysis is carried out according to CEB-FIP 1990 code book and lastly temperature analysis is carried out according to AERB SAFETY STANDARD NO. AERB/SS/CSE-1 and UBC 97, lastly long -term deflection and permissible crack width is evaluated

\section{IV.NUMERICAL MODELING}

Numerical modelling of the Kudankulum containment structure has been developed using finite element based program software named as SAP 2000 as shown in figure 1. Four nodded three dimensional quadrilateral thin shell elements having six DOF are used to develop a nuclear containment structure finite element model. Thin shell element considers both in-plane and out- plane stiffness during the analysis. Totally 1875 nodes and 1850 thin shell elements are used for modelling of super structure.

\section{A. Nuclear containment specifications}

$\begin{array}{ll}\text { Height of the nuclear vault above ground level } & : 64.5 \mathrm{~m} \\ \text { Height of the nuclear vault below ground level } & : 9 \mathrm{~m} \\ \text { Diameter of the Vault } & : 50 \mathrm{~m} \\ \text { Thickness of shear wall } & : 1.2 \mathrm{~m}\end{array}$

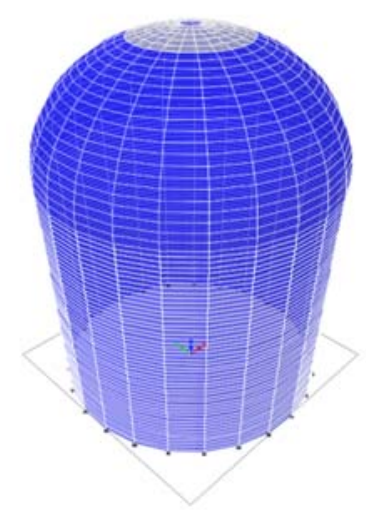

Figure 1: Numerical Nuclear Vault Model 


\section{B. Material properties}

Elastic material model is used to simulate the structure of receiving material as an atomic regulation structure is designed to accommodate elastic limits based on the assumptions limit state criteria. Reinforcement shall be conforming to IS 1786. HYSD bars of Grade Fe550 and Concrete shall be confirming to IS 456 and OPC conforming to IS 12269 and aggregates confirming to IS 383 shall be used for concrete.

Table 1: Material Properties

\begin{tabular}{|l|l|l|l|l|l|l|}
\hline Name & \multicolumn{1}{|c|}{ Type } & symmetrical & \multicolumn{1}{|c|}{$\mathbf{E}$} & $\mathbf{N}$ & Unit Weight & Design Strengths \\
\hline & & Direction & $\mathrm{MPa}$ & & $\mathrm{kN} / \mathrm{m}^{3}$ & $\mathrm{Mpa}$ \\
\hline M60 & Concrete & Isotropic & 38729.83 & 0.2 & 24.9926 & $\mathrm{Fc}=60$ \\
\hline HYSD550 & Rebar & Uni-axial & 200000 & 0.3 & 76.9729 & $\mathrm{Fy}=550, \mathrm{Fu}=585$ \\
\hline
\end{tabular}

Where,

E- Modulus of elasticity

N- Poisson's Ratio

\section{Static ANd Dynamic LoAdS}

\section{A. Dead loads}

Dead loads are considered according to IS 875 (PART 1)-1987 and according to density of possible dead loads. In the present study to reduce the complexity of calculation self-weight of structure is calculated by program itself.

\section{B. Earthquake and Wind parameters}

Equivalent static earthquake load and wind load parameters are taken as per the specification of kudunkulam Nuclear power plant site location according to I.S 1893 (Part 4) 2005 and I.S 875 (part 3) respectively, Kudunkulam Nuclear power plant falls in Zone II, But in the present study it is assumed as zone III as it is a very important structure and very closer to zone III. Seismic and wind parameters incorporated in the present study are tabulated below.

Table 2 Earthquake and wind Parameters

\begin{tabular}{|c|c|c|}
\hline Parameter & Values & Reference \\
\hline \multicolumn{3}{|c|}{ Earthquake Parameters } \\
\hline Zone factor $(Z)$ & 0.16 & From Table number 2 of IS 18932002 \\
\hline Reduction factor $(\mathrm{R})$ & 3 & From Table number 3 of IS 1893 (Part4)2005 \\
\hline Importance factor ( I) & 2 & From Table 2 of IS 1893 (Part4) 2005 \\
\hline Soil Type Category & 2 & From table 1 of IS 18932002 \\
\hline Seismic acceleration coefficient & 1.67 & From 6.4 .5 clause of IS 18932002 \\
\hline Time Period & 0.95 & Clause Number 7.6.2 of IS 1893 (Part1)2002 \\
\hline \multicolumn{3}{|c|}{ Wind Parameters } \\
\hline Wind speed & $9.8 \mathrm{~m} / \mathrm{s}$ & Average wind speed at kudunkulam \\
\hline Structure Class & $\mathrm{B}$ & 5.3.2.1 clause of I.S 875 part 3 \\
\hline Terrain Category & 2 & 5.3.2.1 clause of I.S 875 part 3 \\
\hline Risk coefficient $K_{1}$ & 1 & 5.3.1 clause of I.S 875 part 3 \\
\hline Topography coefficient $\mathrm{K}_{2}$ & 1 & 5.3 .3 clause of I.S 875 part 3 \\
\hline External Pressure Coefficient & & Table 15 fig number b of I.S 875 part 3. \\
\hline
\end{tabular}




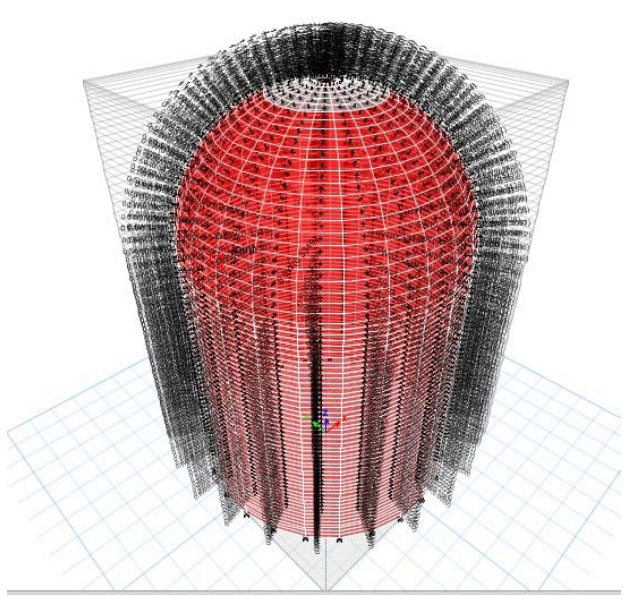

Figure 2: External Wind Pressure Coefficient

\section{VI.LONG TERM NON-LINEAR ANALYSIS}

The major difference between linear analysis and non-linear analysis is stiffness will remain constant, loading and un-loading path are simple in nature, simple analysis procedure in linear analysis where as in non-linear analysis there is variation of stiffness, loading and unloading paths are complex in nature and complex analysis procedure.

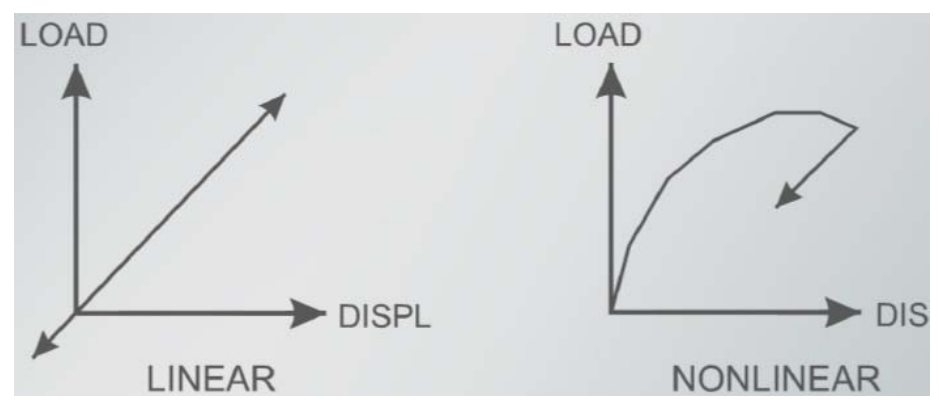

Figure 3: Linear Behaviour versus Non-Linear Behaviour

Zero Initial Conditions -Start from Unstressed State: The structure having zero velocity and displacement, absence of past non-linear deformation.

\section{A. Material Non-linearity}

Material non linearity occurs when there is non-linear stress-strain behaviour is observed in the material and there will change in material properties with respect to varying loads. Non-linear behaviour for M60 grade and HYSD 550 is shown in figure

In the present study for material non-linearity creep and shrinkage analysis are carried out according CEBFIP-1990 EURO code, creep and shrinkage analysis are generally carried out by two methods namely the Dirichlet series method and the full integration method. Creep Coefficient and shrinkage strain are determined manually as well as analytically.

Linear and non-linear behaviour of M60 grade concrete is shown in below figure 4 


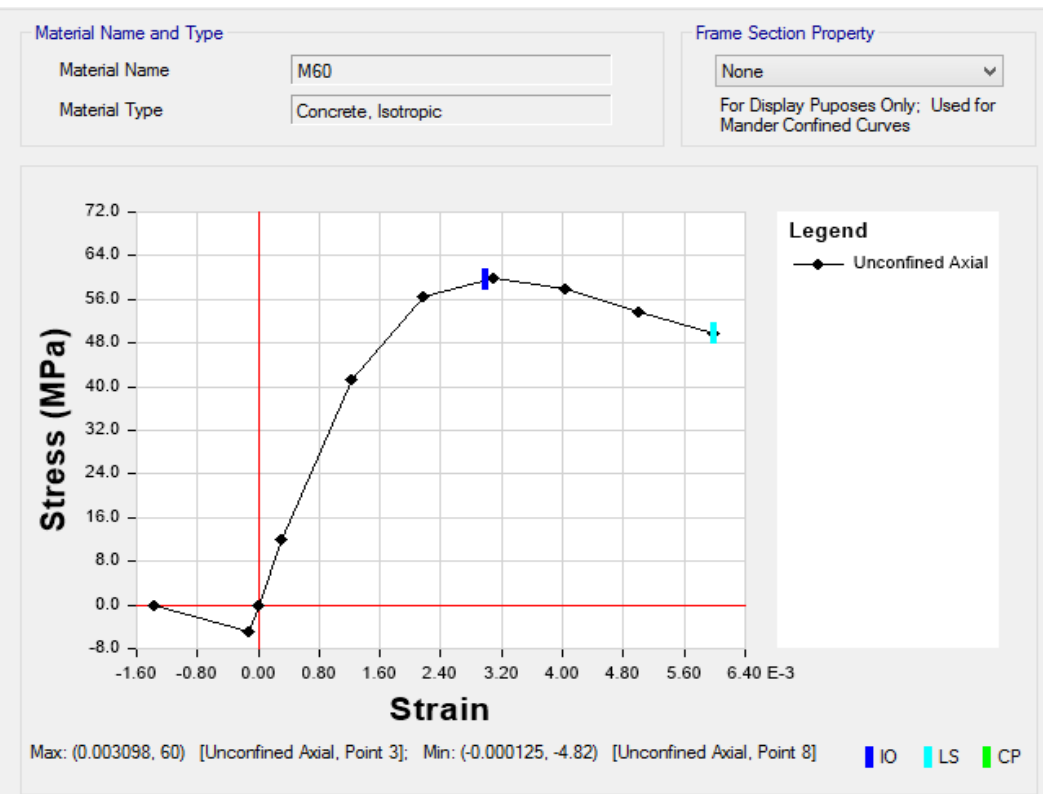

Figure 4 Stress Strain Curve for M60 Grade Concrete

Linear and non-linear behaviour of HYSD 550 grade rebar is shown in below figure 5

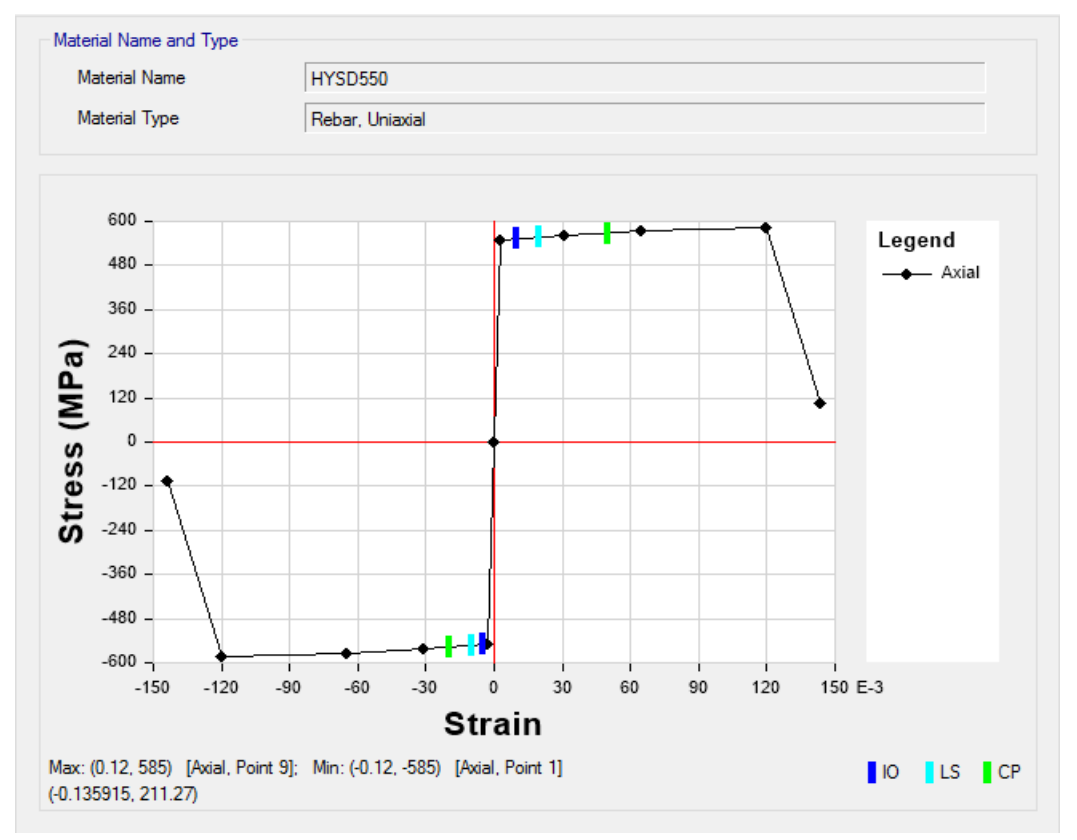

Figure 5 Stress Strain Curve for HYSD 550 Grade Rebar

\section{A.1Theoretical Calculation}

- Relative humidity is taken as $50 \%$ as per the specification of Kudankulam Nuclear power plant site location.

- Notional size (n)

- From equation 2.1 -69 of CEB-FIP 1990 code book

- $=\frac{2 A c}{U}$, where Ac is cross sectional area of one element and $\mathrm{u}$ is perimeter

- $=\frac{2 \times 6.27}{14.53}=862.8 \mathrm{~mm}$.

- Shrinkage start age is taken as $\quad=7$ hours

- Age of loading $=7$ days 
Creep coefficient and shrinkage strain are calculated according to clause 2.1.6.4 of CEP-FIP 1990 Total shrinkage strain calculated as follows:

\section{Total shrinkage strain is given as:}

From equation 2.1 -74 of CEB-FIP 1990 code book

$\varepsilon_{\mathrm{s}}\left(\mathrm{t}, \mathrm{t}_{\mathrm{s}}\right)=\varepsilon_{\mathrm{cso}} \beta_{\mathrm{s}}(\mathrm{t}-\mathrm{ts})$

\section{Where:}

$\beta_{\mathrm{s}}=$ coefficient to know rate of shrinkage development equation 2.1-79 of CIB-FIP 1990

$\mathrm{t}=$ Concrete age measured in days

ts $=$ Age of concrete at the time of shrinkage beginning in days

Notional Shrinkage coefficient:

From equation 2.1-75 of CEB-FIP 1990 code book

$\varepsilon_{\mathrm{cso}}=\varepsilon_{\mathrm{S}} \mathrm{x}(\mathrm{fcm}) \times \beta_{\mathrm{RH}}$

$$
\begin{aligned}
\varepsilon_{\mathrm{s}}(\mathrm{fcm})= & \mathrm{X} 10^{-6}\left[160+10 \times \beta_{\mathrm{sc}}\left(9-\frac{f c m}{f c m o}\right)\right] \\
& =\left[160+10 \times 8\left(9-\frac{60}{10}\right)\right] \times 10^{-6} \\
& =400 \times 10^{-6}
\end{aligned}
$$

\section{Where:}

$\mathrm{fcm}=28$ days mean compressive strength of concrete measured in $\mathrm{MPa}$

$\mathrm{fcmo}=10 \mathrm{MPa}$

$\beta_{\mathrm{sc}}=$ coefficient depends on the type of cement

$=8$ for rapid hardening high strength

$\mathrm{RH}=$ Relative humidity as per ambient temperature

$\mathrm{RH}_{0}=100 \%$

As relative humidity is between $40 \%<<\mathrm{RH}<<99 \%$

$\beta_{\mathrm{RH}}=-1.55 \beta_{\mathrm{s} R}$

Where:

$$
\begin{aligned}
\mathrm{B} \mathrm{S}_{\mathrm{RH}} & =1-\left(\mathrm{RH} / \mathrm{RH}_{0}\right)^{3} \\
& =1-(50 / 100)^{3} \\
& =0.875
\end{aligned}
$$

Therefore,

$$
\begin{gathered}
\beta_{\mathrm{RH}}=-1.55 \beta_{\mathrm{SRH}} \\
=-1.55 \times 0.875 \\
=-1.36
\end{gathered}
$$

Therefore shrinkage coefficient $=400 \times 10^{-6} \times 1.36$

$$
=0.000544
$$

Designed for 100 years

\section{Shrinkage development rate is given by:}

$$
\begin{aligned}
\beta_{\mathrm{s}}(\mathrm{t}-\mathrm{ts})= & \left(\frac{(t-t s) / t 1}{\left.350\left(\frac{h}{h o}\right)^{2}+(t-t s) / t 1\right)}\right)^{0.5} \\
= & \left(\frac{(36500-1) / 1}{\left.350\left(\frac{862.3}{10 o}\right)^{2}+(36500-1) / 1\right)}\right)^{0.5} \\
& =0.7632
\end{aligned}
$$

\section{Where:}

ho $=100 \mathrm{~mm}$

$\mathrm{t} 1=1$ day

$\mathrm{t}=$ life span of concrete measured in days

ts $=$ Age of concrete at the time of shrinkage beginning measured in days i.e 1 day 


\section{There total shrinkage strain}

$$
\begin{aligned}
\varepsilon_{\mathrm{s}}\left(\mathrm{t}, \mathrm{t}_{\mathrm{s}}\right)= & \varepsilon_{\mathrm{cso}} \beta_{\mathrm{s}}(\mathrm{t}-\mathrm{ts}) \\
= & 0.76 \times 0.000544 \\
& =0.000415
\end{aligned}
$$

\section{Creep coefficient calculation:}

From equation 2.1-64 of CEB-FIP 1990 code book

$\Phi\left(\mathrm{t}, \mathrm{t}_{0}\right)=\varphi_{\mathrm{o}} \beta_{\mathrm{s}}\left(\mathrm{t}-\mathrm{t}_{\mathrm{o}}\right)$

Where: $\varphi_{0}=$ notional creep coefficient

$\beta_{\mathrm{s}}=$ coefficient to describe the development of creep after the time of loading

$$
\begin{aligned}
\mathrm{t} & =\text { Age of concrete at moment considered } \\
\mathrm{t}_{0} & =\text { Age of concrete at loadings }
\end{aligned}
$$

\section{Notional creep coefficient is given by:}

From equation 2.1-65 of CEB-FIP 1990 code book

$\varphi_{\mathrm{o}}=\varphi_{\mathrm{RH}} \mathrm{X} \beta(\mathrm{fcm}) \times \beta\left(\mathrm{t}_{0}\right)$

Where: $h=$ notional size

$\mathrm{fcm}=$ mean compressive strength of concrete at age of 28days in $\mathrm{MPa}$

$\mathrm{fcmo}=10 \mathrm{MPa}$

$\mathrm{t} 1=1$ day

$\mathrm{t}=36500$ days

$\mathrm{t}_{\mathrm{o}}=$ Age of concrete at the loading days i.e 7 days

$\mathrm{RH}=$ Relative humidity as per ambient temperature $=50 \%$

$\mathrm{RH}_{0}=100 \%$

$$
\begin{aligned}
& \begin{aligned}
\varphi_{\mathrm{RH}}= & 1+\frac{1-\frac{R H}{R H 0}}{0.46 x\left(\frac{h}{h 0}\right)^{1} / 3} \text { (from equation 2.1-66 of CEB-FIP } 1990 \text { code book) } \\
= & 1+\frac{1-\frac{50}{100}}{0.46 x\left(\frac{862.3}{100}\right)^{1} / 3} \\
= & 1.5299
\end{aligned} \\
& \beta(\mathrm{fcm})=\frac{5.3}{\left(\frac{f c m}{f c m 0}\right)^{0.5}} \quad \text { (from equation 2.1-67 of CEB-FIP } 1990 \text { code book) } \\
& =\frac{5.3}{\left(\frac{60}{10}\right)^{0.5}} \\
& =2.1637 \\
& \beta\left(\mathrm{t}_{0}\right)=\frac{1}{0.1+\left(\frac{t 0}{t 1}\right)^{0.2}} \quad \text { (from equation 2.1-68 of CEB-FIP } 1990 \text { code book) } \\
& =\frac{1}{0.1+\left(\frac{7}{1}\right)^{0.2}} \\
& =0.63
\end{aligned}
$$

Therefore notional creep coefficient $=\varphi_{0}=\varphi_{R H} X \beta(\mathrm{fcm}) \times \beta\left(\mathrm{t}_{0}\right)$

$$
=0.63 \times 2.163 \times 1.53
$$

$$
=2.100
$$

\section{Creep coefficient:}

$$
\begin{aligned}
& \Phi\left(\mathrm{t}, \mathrm{t}_{0}\right)=\varphi_{\mathrm{o}} \beta_{\mathrm{s}}\left(\mathrm{t}-\mathrm{t}_{\mathrm{o}}\right) \\
& \beta_{\mathrm{s}}(\mathrm{t}-\mathrm{t} 0)=\left(\frac{(t-t 0) / t 1}{\beta \mathrm{H}+(t-t 0) / t 1)}\right)^{0.3} \\
& =\left(\frac{(36500-7) / 1}{1500+(36500-7) / 1)}\right)^{0.3} \\
& =0.987
\end{aligned}
$$

$\beta \mathrm{H}=150\left\{1+(1.2 \times \mathrm{RH} / \mathrm{RH} 0)^{18}\right\} \mathrm{h} / \mathrm{h} 0+250<=1500$ as per clause $2.1-70$

Therefore creep Coefficient $=\Phi\left(\mathrm{t}, \mathrm{t}_{0}\right)=\varphi_{\mathrm{o}} \beta_{\mathrm{s}}\left(\mathrm{t}-\mathrm{t}_{\mathrm{o}}\right)$ 


$$
\begin{aligned}
& =2.1 \times 0.987 \\
& =2.058
\end{aligned}
$$

\section{B. Geometric Non-linearity}

Geometric non-linearity can happen because of huge amount of relocations and rotations of structure and substantial strains developed in the structure it includes nonlinearity in kinematic quantities such as the strainrotation, stress-strain, strain- deflection relations in basic structural components.

P-Delta effect is known as the geometric nonlinearity, it is the secondary effect on moment and shear of the structural members occurring due to interaction of vertical loads and lateral displacement of the structure resulting from lateral loads like earthquake, wind.

In the present study P-delta analysis is carried out according to IS 1893 part 12002 and UBC 97 code book using ETABS program P-delta load combination is repetitive resulting in more computational time of the analysis. Structure undergoes local buckling of the individual members are global buckling of the entire structure if P-Delta compressive axial forces are in large quantity. Buckling of whole structure results somewhat unpredictable deformation and failure mode of the structure.

\section{A. Temperature loads}

$+50 \mathrm{C}$ Temperature load is assigned to nuclear containment structure

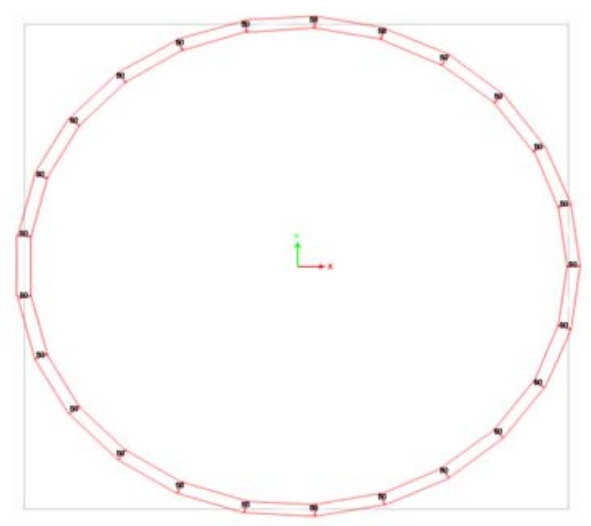

Figure 6 Temperature Loa

\section{B. Non-linear loads}

Non-linearity loads are defined by creating static nonlinear staged construction cases that are specifically tailored to model construction sequence loading.

A non-linear stage is defined as a collection of operations that are executed at a given time. Each stage has defined in terms of number of days to complete that defined stage. The first stage will start with the initial conditions defined for the Staged-Construction Load Case and each stage starts with initial conditions equal to the end of the previous Stage.

In the present study each story of the nuclear containment structure is adopted as one stage. Number of days for construction of these stages is assumed based on earlier study. Stage 52 is the spherical dome, number of days for construction of the erection of the spherical dome is assumed as 109 days. After construction stages are the maintenance stages defined at every 20 years life span of nuclear containment structure 
Table 3 Non-Linear Staged Loads

\begin{tabular}{|c|c|c|c|c|}
\hline Construction Height & Stage Name & $\begin{array}{c}\text { Stage Start } \\
\text { Age }\end{array}$ & Duration & $\begin{array}{c}\text { Cumulative } \\
\text { Dead load }\end{array}$ \\
\hline $\mathbf{M}$ & & Days & days & Stages \\
\hline 1.5 & Stage 1 & 0 & 54 & 0 \\
\hline 1 & Stage 2 & 54 & 35 & Stage 1 \\
\hline 1 & Stage 3 & 89 & 35 & Stage 2 \\
\hline 1 & Stage 4 & 124 & 35 & Stage 3 \\
\hline 1 & Stage 5 & 159 & 35 & Stage 4 \\
\hline 1 & Stage 6 & 194 & 35 & Stage 5 \\
\hline 1 & Stage 8 & 229 & 35 & Stage 6 \\
\hline 1 & Stage 8 & 264 & 35 & Stage 7 \\
\hline 1 & Stage 9 & 299 & 35 & stage 8 \\
\hline 1 & Stage 10 & 334 & 35 & stage 9 \\
\hline 1 & Stage 11 & 369 & 35 & stage 10 \\
\hline 1 & Stage 12 & 404 & 35 & stage 11 \\
\hline 1 & Stage 13 & 439 & 35 & stage 12 \\
\hline 1 & Stage 14 & 474 & 35 & stage 13 \\
\hline 1 & Stage 15 & 509 & 35 & stage 14 \\
\hline 1 & Stage 16 & 544 & 35 & stage 15 \\
\hline 1 & Stage 17 & 579 & 35 & stage 16 \\
\hline 1 & Stage 18 & 614 & 35 & stage 17 \\
\hline 1 & Stage 19 & 649 & 35 & stage 18 \\
\hline 1 & Stage 20 & 684 & 35 & stage 19 \\
\hline 1 & Stage 21 & 719 & 35 & stage 20 \\
\hline 1 & Stage 22 & 754 & 35 & stage 21 \\
\hline 1 & Stage 23 & 789 & 35 & stage 22 \\
\hline 1 & Stage 24 & 824 & 35 & stage 23 \\
\hline 1 & Stage 25 & 859 & 35 & stage 24 \\
\hline 1 & Stage 26 & 894 & 35 & stage 25 \\
\hline 1 & Stage 27 & 929 & 35 & stage 26 \\
\hline 1 & Stage 28 & 964 & 35 & stage 27 \\
\hline 1 & Stage 29 & 999 & 35 & stage 28 \\
\hline 1 & Stage 30 & 1034 & 35 & stage 29 \\
\hline 1 & Stage 31 & 1069 & 35 & stage 30 \\
\hline 1 & Stage 32 & 1104 & 35 & stage 31 \\
\hline 1 & Stage 33 & 1139 & 35 & stage 32 \\
\hline 1 & Stage 34 & 1174 & 35 & stage 33 \\
\hline 1 & Stage 35 & 1209 & 35 & stage 34 \\
\hline 1 & Stage 36 & 1244 & 35 & stage 35 \\
\hline 1 & Stage 37 & 1279 & 35 & stage 36 \\
\hline 1 & Stage 38 & 1314 & 35 & stage 37 \\
\hline 1 & Stage 39 & 1349 & 35 & stage 38 \\
\hline 1 & Stage 40 & 1384 & 35 & stage 39 \\
\hline 1 & Stage 41 & 1419 & 35 & stage 40 \\
\hline 1 & Stage 42 & 1454 & 35 & stage 41 \\
\hline
\end{tabular}




\begin{tabular}{|c|c|c|c|c|}
\hline 1 & Stage 43 & 1489 & 35 & stage 42 \\
\hline 1 & Stage 44 & 1524 & 35 & stage 43 \\
\hline 1 & Stage 45 & 1559 & 35 & stage 44 \\
\hline 1 & Stage 46 & 1594 & 35 & stage 45 \\
\hline 1 & Stage 47 & 1629 & 35 & stage 46 \\
\hline 1 & Stage 48 & 1664 & 35 & stage 47 \\
\hline 1 & Stage 49 & 1699 & 35 & stage 48 \\
\hline 1 & Stage 50 & 1734 & 35 & stage 49 \\
\hline 1 & Stage 51 & 1769 & 35 & stage 50 \\
\hline Spherical dome 50m & Stage 52 & 1804 & 109 & stage 51 \\
\hline After construction & Stage 53 & 1913 & 7300 & stage 52 \\
\hline After construction & Stage 54 & 9213 & 7300 & stage 53 \\
\hline After construction & Stage 55 & 16513 & 7300 & stage 54 \\
\hline After construction & Stage 56 & 23813 & 7300 & stage 55 \\
\hline After construction & Stage 57 & 3111 & 7300 & stage 56 \\
\hline
\end{tabular}

\section{RESULTS}

\section{A. Short term deflection}

Maximum deflection due to static load is $2.3 \mathrm{~mm}$ as shown in figure 7

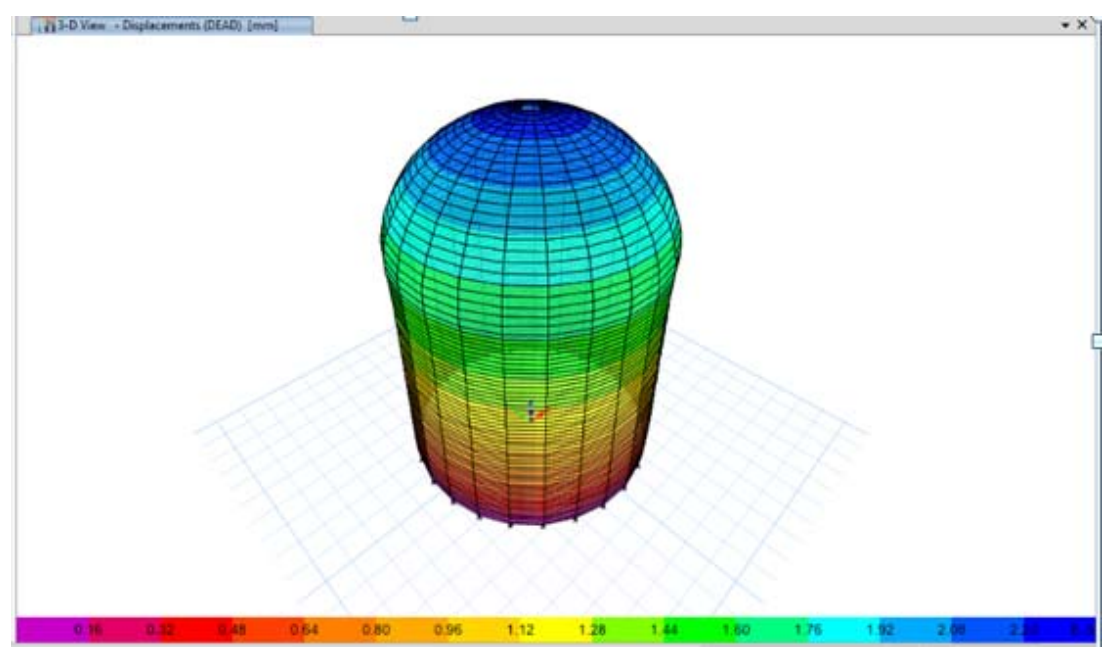

Figure 7: Deflection for Gravity Load

\section{B. Creep Coefficient}

Analytically maximum creep coefficient obtained for full-integration method for period of 100 years is 1.949 as shown in figure 8 


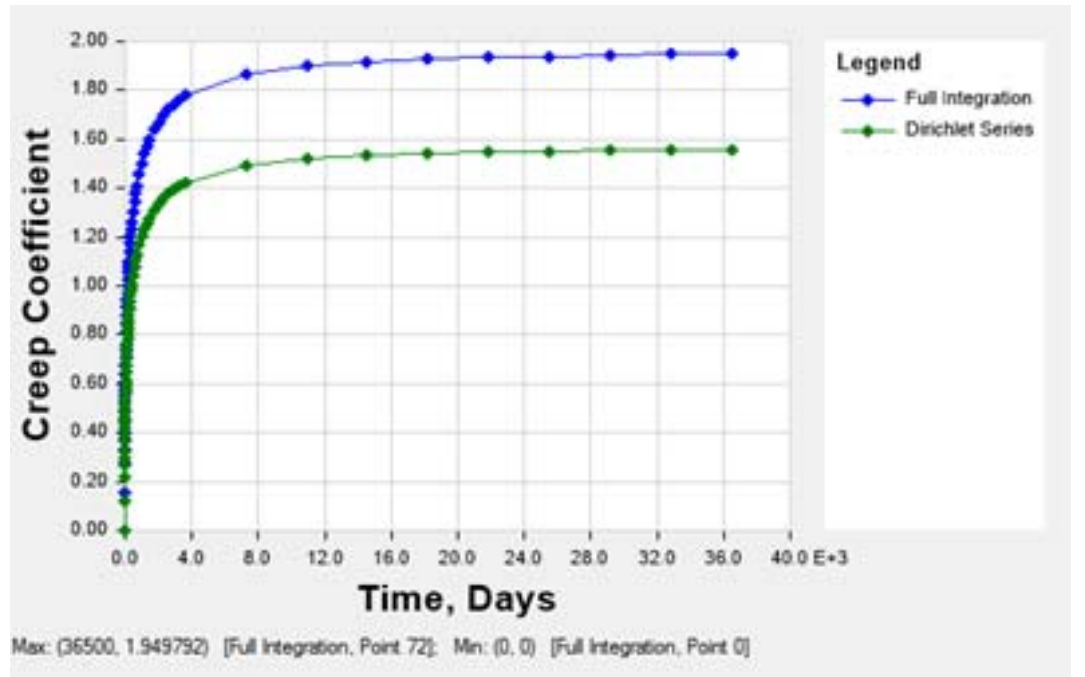

Figure 8: Analytical Creep Coefficient

\section{Shrinkage strain}

Analytically maximum shrinkage strain obtained for period of 100 years is 0.000348 as shown in figure 9

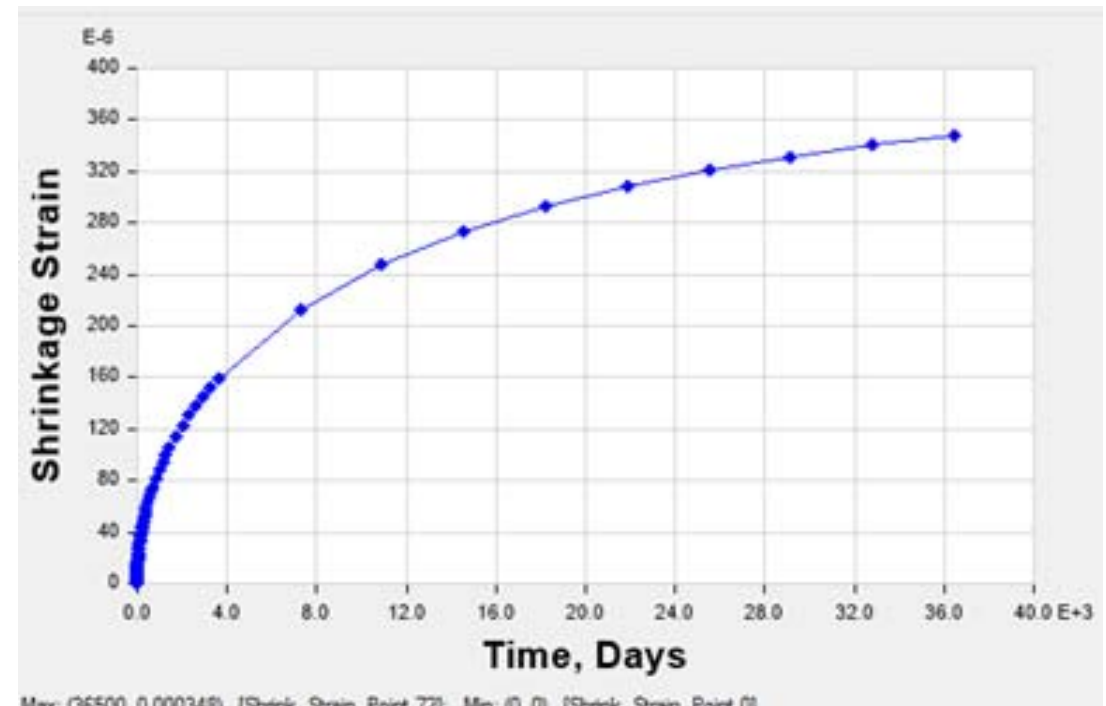

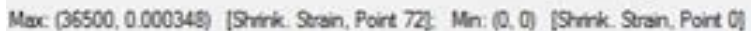

Figure 9: Analytical Shrinkage Strain

D. Comparison of results

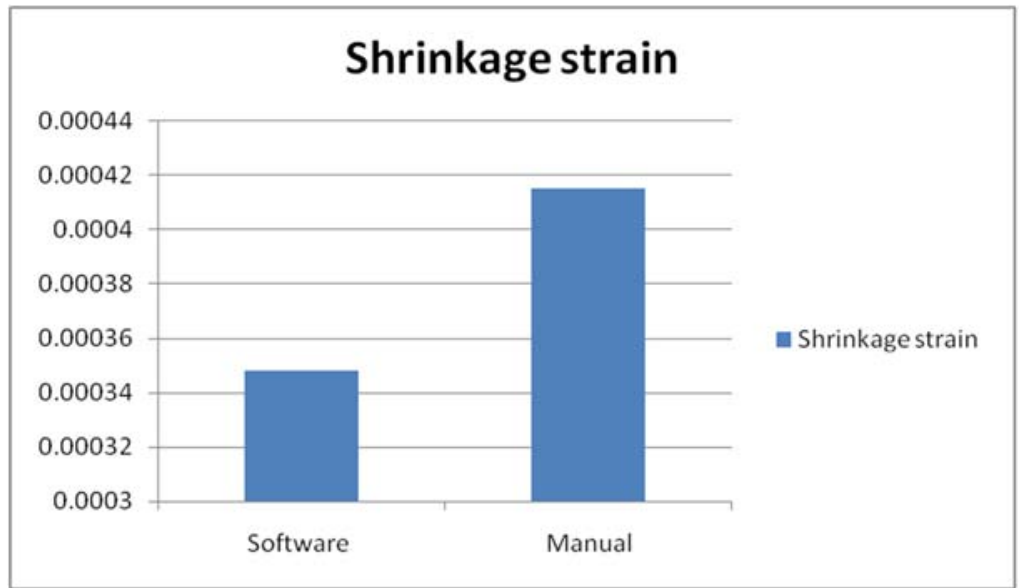

Figure 10 Theoretical and Analytical Shrinkage Strain 


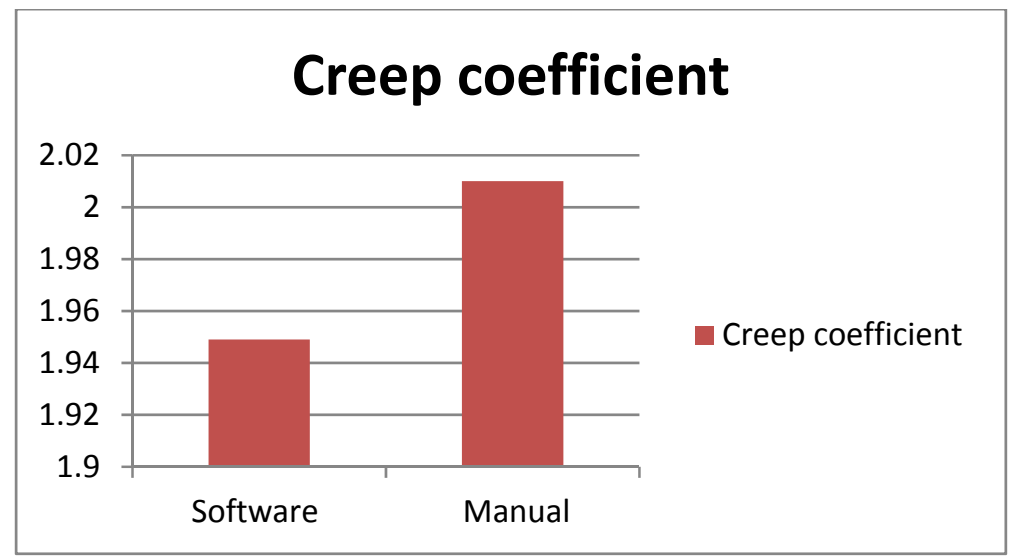

Figure 11 Theoretical and Analytical Creep coefficient

\section{E. Temperature}

Maximum Temperature load obtained analytically is $12843 \mathrm{kN}$ as shown in figure 12

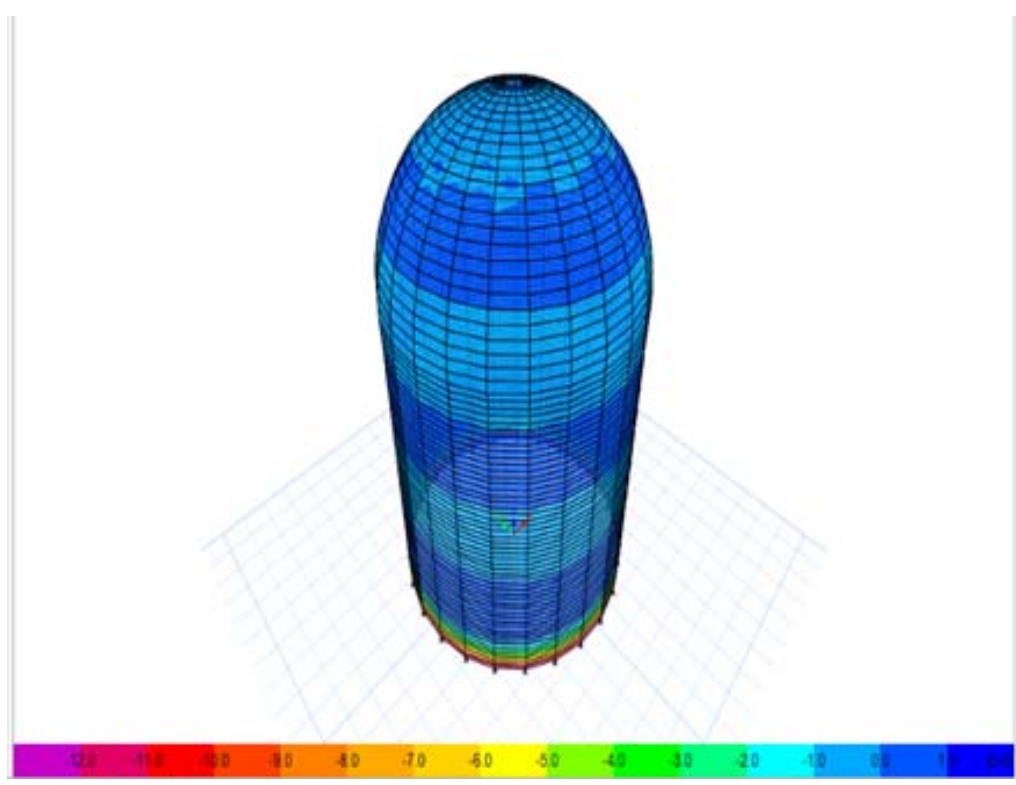

Figure 12 Maximum Temperature Load

\section{F. $\quad$ Long term deflection:}

According to I.S 456 Clause 23.2

The deflection including effects of creep, shrinkage and temperature occurring after the erection and application of finishes should not normally exceed $20 \mathrm{~mm}$ or span $/ 350$ whichever is less

$50000 / 350(144.3 \mathrm{~mm})$ or $20 \mathrm{~mm}>18.2 \mathrm{~mm}$ hence deflection for period of 100 years are within permissible limit As shown in figure 13 


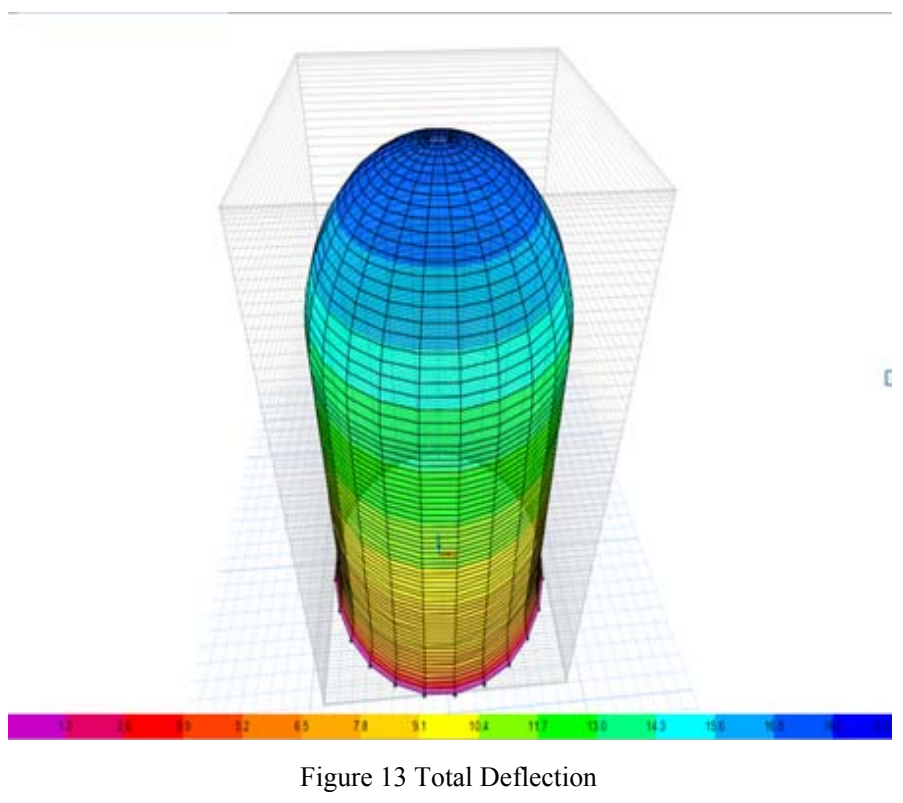

VIII. CONCLUSION

- Short term deflection due to gravity load is $2.3 \mathrm{~mm}$

- Creep Coefficient obtained for numerical model is 1.949 whereas for theoretical calculation the value obtained is 2.01. Hence analytical creep Coefficient results are in good agreement with theoretical results

- Shrinkage strain obtained for numerical model and manual calculation are 0.000348 and 0.000415 respectively hence analytical shrinkage strain are quite near to the theoretical results

- Long term deflection including the effects of creep, shrinkage and temperature occurring after the erection and application of finishes is $18.2 \mathrm{~mm}$ hence it is within the permissible limit according to Clause 23.2 of I.S 4562000 .

\section{IX.ACKNOWLEDGMENT}

I thank Mr. SANDEEP PINGALE MD E-construct Design and Build Pvt. Ltd for offering this project.

\section{REFERENCES}

[1] Banti A. Gedam, A. U. (2009). An Apt Material Model to Predict Creep and Shrinkage Behavior of HPC Concrete. Third international conference on sustainable construction material and technologies, (p. 10). Rorkee.

[2] Rashid, J. Y. (2010). Modeling and analysis of aging behavior of concrete structures.Fontevraud 7 science direct, 12.

[3] ASCE, 2007. Seismic Rehabilitation of Existing Buildings, ASCE 41-06, Structural Engineering Institute, Reston, VA.

[4] F. H. Wittmann, F. H. (1982). Creep And Shrinkage In Concrete Structures.Chkhcster . New York Brishanc . Toronto' Singapore: A Wiley-Interscience Publication.

[5] Haranki, B. (2009). Strength, Modulus Of Elasticity, Creep And Shrinkage Of Concrete. Florida.

[6] HCC. (2014). Making Of Kudankulam Nuclear Power Plant. Kudanlulam .

[7] Y.T. Praveenchandra, R. R. (2014). Structural Monitoring And Response Analysis Of Prestressed Concrete Primary Containment Of A Nuclear Power Plant. 1st International Conference On Structural Integrity, ICONS-2014 (P. 6). Mumbai India: Procedia Engineering 86 ( 2014 ) 554 - 559 Science Direct And Elsevier.

[8] Sohini Sarkar, D. S. (2011). Effects Of Various Factors On Durability Prediction Of Nuclear Waste Containment Structures - 11546. WM2011 Conference, (P. 16). Phoenix, USA.

[9] IS 456:(2000) Plain and reinforced concrete code of practise

[10] IS 383-(1970) Specification for coarse and fine aggregate from natural source for concrete

[11] 875 part1:(1997) Code of practise for design loads (Other than earthquake) for buildings and structures

[12] G. Ruocci, P. B. (2012). Cracks Distance And Width In Reinforced Concrete. 15WCEE, (P. 10). LISB0V.

[13] CEB-FIP -1990 Euro code

[14] AERB SAFETY GUIDE NO. AERB/NPP-PHWR/SG/D-23,

\section{AUTHOR PROFILE}

${ }^{1}$ Niteesh H. M.TECH Student of civil Department M .S RamaiahUniveristy of Applied Science.

${ }^{2}$ Dr. Rajashekar Swamy Professor and Head of civil Department M .S RamaiahUniveristy of Applied Science

${ }^{3}$ Santhosh H. P. Assistant Professor of civil DepartmentM .S RamaiahUniveristy of Applied Science 